\title{
A SCIENTOMETRIC REVIEW OF WATER RESEARCH ON THE YANGTZE RIVER
}

\author{
CHEN, D. ${ }^{1,5}-$ BI, B. ${ }^{1}-$ LUO, Z. H. $.^{2,5}{ }^{*}-$ YANG, Y. W. ${ }^{3}-$ WeBBER, M. ${ }^{4}-$ FinlaYson, B. ${ }^{4}$ \\ ${ }^{1}$ Key Laboratory of Efficient Irrigation-Drainage and Agricultural Soil-Water Environment in \\ Southern China (Ministry of Education), College of Agricultural Sciences and Engineering, \\ Hohai University \\ Nanjing 210098, Jiangsu Province, P. R. China \\ ${ }^{2}$ College of Resources and Environmental Sciences, Nanjing Agricultural University \\ Nanjing 210095, Jiangsu Province, P. R. China \\ ${ }^{3}$ Nanjing Institute of Environmental Sciences, MEP, \\ Nanjing 210042, Jiangsu Province, P. R. China \\ ${ }^{4}$ School of Geography, The University of Melbourne \\ Parkville 3010, Victoria, Australia \\ ${ }^{5}$ Department of Agricultural and Biological Engineering, the University of Florida \\ Gainesville 32611, USA \\ *Corresponding author \\ e-mail: lzhui@njau.edu.cn; phone: +862584395815 \\ (Received $15^{\text {th }}$ Aug 2018; accepted $16^{\text {th }}$ Oct 2018)
}

\begin{abstract}
With the traditional literature review, a bibliometric analysis of water research on the Yangtze River from 1996 to 2016 was presented on the Science Citation Index Expanded (SCI-Expanded) and Social Science Citation Index (SSCI) of the Web of Science database. This analysis revealed a quantitative and visual global scientific research review from the aspects of document type and language, publication year, authorship, subject categories and journals, countries or territories and institutions, the most-frequently cited publications, author keywords and research trends. The annual number of publications in this field has rapidly increased over the past decade. The 20 most productive authors were all Chinese. The journals of Environmental Science and Pollution Research, Environmental Earth Sciences and Journal of Hydrology were the three most common journals. China produced $90.4 \%$ of all pertinent publications followed by the USA (13.7\%) and Japan (4.0\%). The Chinese Academy of Sciences was the major institution, producing $31.9 \%$ of all publications. The most frequently cited publications and author keywords provided the clues for research focuses. The hotspots and trends in this field included the impacts of climate change and human activities and the adaptation strategies. Additional studies should also be focused on water conservancy development, environmental issues and solutions and the WaterFood-Energy nexus.
\end{abstract}

Keywords: bibliometric analysis, research trend, visualization, Web of Science, Citespace

\section{Introduction}

Climate change and human activity have been affecting the streamflow of many river basins and the sustainability of river ecosystems. In the current complex and interconnected world, some problems in a river basin at a local level have large-scale effects and even become global issues. The situation in the Yangtze River of China was typical of this trend. For instance, the Yangtze River has been observed to be the world's biggest polluter in all rivers, concerning pollution of the marine environment with plastic debris (Schmidt et al., 2017). Its changes in sediment, pollutants and water 
discharge to the sea have great impacts on the marine ecology (Wang et al., 2015; Yang et al., 2015). The Three Gorges Dam might be a major source of greenhouse gas emissions (Qiu, 2009; Zhao et al., 2013). The high species richness of the Yangtze River has been seriously threatened by human activities. In 2006 the Baiji dolphin became extinct, which caused that the world lost an entire genus (Zhou et al., 2018). Therefore, the Yangtze River is of vital importance not only for China but also the world. The review of scientific studies on the Yangtze River will enhance understanding about research progresses, current situation and future trends, to the benefit of theory research and practice in the conservation and sustainable development of global rivers.

The Yangtze River is the longest river in Asia and the third longest in the world, running a 6,300-kilometer course from glaciers on the Qinghai-Tibet plateau into the East China Sea near Shanghai (Fig. 1) (Chen et al., 2013). The Yangtze River has more than 3,000 tributaries and 4,000 lakes (Zeng, 1990). It is the longest in the world to flow entirely within one country. The Yangtze River basin supports one third of China's population and produces more than $40 \%$ of China's GDP. It plays a vital role in the economic development of China. The huge Yangtze drainage basin, which has a catchment area of $1.94 \times 10^{6} \mathrm{~km}^{2}$, can be divided into the upper, middle and lower Yangtze reaches. The Yangtze River Basin is one of the world's core regions. In particular the Yangtze River Delta, one of China's most developed, dynamic, densely populated and concentrated industrial area, is growing into an influential world-class metropolitan area ( $\mathrm{Gu}$ et al., 2011). The sustainability of the Yangtze River Basin directly affects the regional and sustainable development of China and the world.

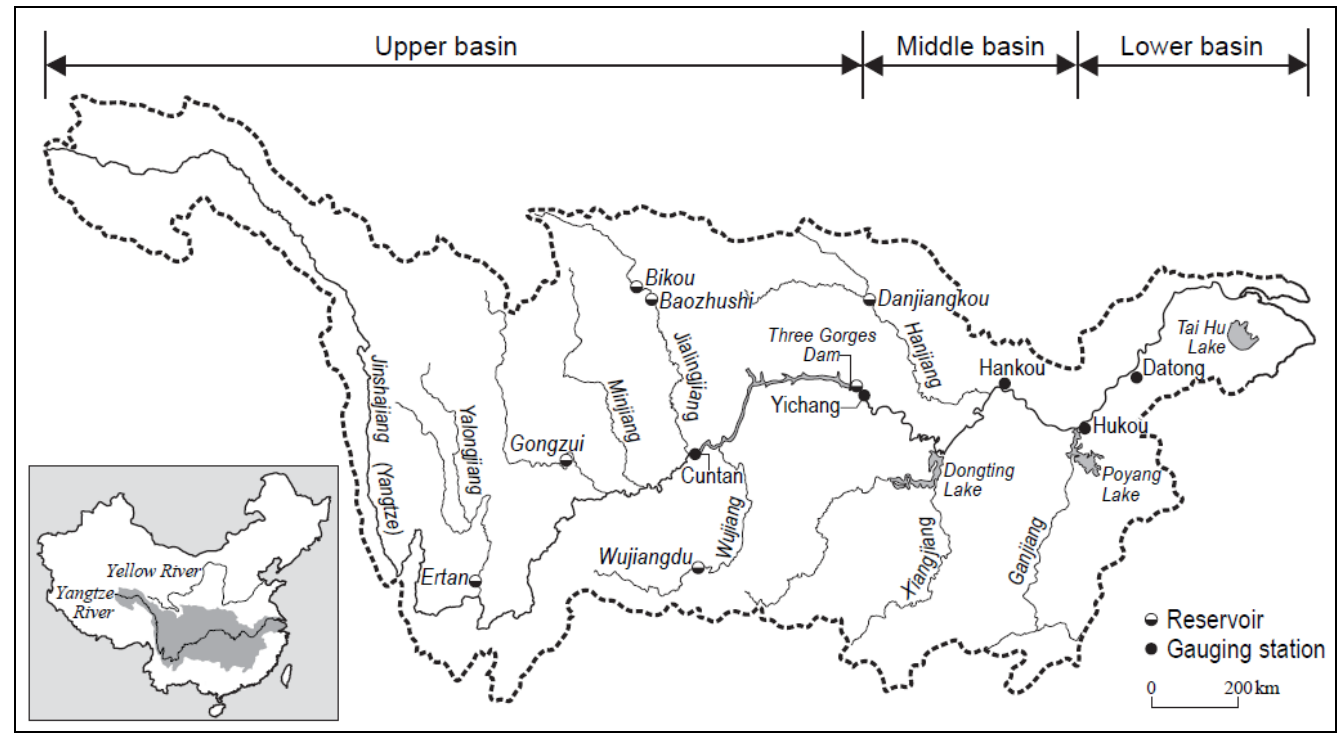

Figure 1. Location diagram and details of the Yangtze River Basin

The Yangtze River Basin is studied by many international organizations, especially in the water research field, due to its rapid economic development and increasingly severe environmental issues. Water issues and problems have gained global attention, such as the ecological protection of the river source area and the Three Gorges Reservoir area, the impacts of the Three Gorges Project, the South to North Water Diversion Project and other large-scale hydraulic projects, flood and drought hazards, water pollution, eutrophication in Taihu lake, and salt intrusions in the Yangtze Estuary. 
With increasing concern about the Yangtze River, a great number of studies have been published in recent years. Significant efforts have been made in water research on the Yangtze River from different academic disciplines, including geography, hydrology, meteorology, engineering, geology, ecology, environment, economics and management. However, few studies attempted to gather global systematic data and conduct a largescale review of scientific studies related to the Yangtze River. To address this literature gap, we attempt to perform a systematic evaluation of peer-reviewed literature concerning the global trends of water research on the Yangtze River from a bibliometric perspective. Moreover, considering the potential limitations of the bibliometric analysis, traditional literature reviews were incorporated into the analysis. To some extent, this study can reveal the hot spots and research trends and provide references for related research in the future.

\section{Methodology and data sources}

The bibliometric and visualization analysis of water research on the Yangtze River was performed in this study. Bibliometrics is a set of methods coined by Alan Pritchard in 1969, to quantitatively review academic literature and describe distribution patterns within a given topic, field, institute or country (Pörtner, 2008). It can identify development trends or future research orientations by analyzing author keywords ( $\mathrm{Li}$ et al., 2009). Bibliometric studies with the statistical analysis of scientific publications adopted quantitative performance indicators to overcome the disadvantage of subjectivity in peer review and expert judgments. This method has been used to assess research performance in an increasing number and variety of studies (Rinia et al., 1998). Citespace software was used in this bibliometric analysis for visualizing trends and patterns in scientific literature. This java application was invented by Chen Chaomei at Drexel University (Chen, 2004). Similar to a camera, Citespace could take snapshots of a particular field based on time sequence and link them together, deducing changing processes and development trends in this field. It focuses on finding critical points in the development of a field, especially intellectual turning points and pivotal points (Chen, 2006). Citespace could provide various functions to facilitate the understanding and interpretation of network patterns and historical patterns, including identifying fastgrowth topical areas and citation hot spots in the land of publications, decomposing a network into clusters, automatically labelling clusters with terms from citing articles, geo-spatial patterns of collaboration, and unique areas of international collaboration. Citespace could also support structural and temporal analyses of a variety of networks derived from scientific publications, including collaboration networks, author cocitation networks, and document co-citation networks. The structure and dynamics of co-citation clusters were interpreted and characterized by using a multiple-perspective co-citation analysis method (Chen et al., 2010). This method extended and enhanced traditional methods in two ways, including integrating structural and content analysis components sequentially into the new procedure, and facilitating analytic tasks and interpretation with automatic cluster labelling and summarization functions. It also supports networks of hybrid node types, such as terms, institutions, and countries, and hybrid link types such as co-citation, co-occurrence, and directed citing links (Chen et al., 2010). Due to the powerful and advanced features, Citespace has received increasing attention and has been widely used. 
The data were based on the online version of Science Citation Index Expanded (SCIExpanded) and the Social Science Citation Index (SSCI) of the Web of Science database from 1996 to 2016. The SCI and SSCI databases are regarded as the most frequently used and robust databases for bibliometric studies (Liu et al., 2011). The online version of SCI-Expanded and SSCI was searched under the theme keywords (including title keywords, keywords in abstract and author keywords) of "Yangtze River Or Chang River" and "Yangtze river And water Or Chang River And water", respectively. The number of publications identified using these two-theme keywords were 7,321 and 3,093. In this study, we focused on the keyword "Yangtze River And water Or Chang River And water" and chose the 3,093 publications for further study.

The reported impact factor (IF) of each journal was obtained from the 2015 edition of the Journal Citation Reports (JCR), which was published in 2014 by the Institute for Scientific Information (ISI). All documents were downloaded on April 11, 2017 from the database and analyzed with bibliometric techniques along with Citespace. With the help of traditional literature review, all publications from 1996-2016 were assessed by the following aspects: document type and language of publications, characteristics of publication outputs, authorship, distribution of output in subject categories and journals; publication outputs of country, institute, the most frequently cited publications, author keywords and research trends.

\section{Results and discussion}

\section{Document types and language of publication}

Eight document types were identified in the total 3,093 publications. Journal article (3030) was the most-frequently used document type, comprising $97.96 \%$ of the total productions, followed distantly by proceedings paper $(139 ; 4.49 \%)$ and review (54; $1.75 \%$ ). The others with less significance were book chapter (5), letter (3), editorial material (3), meeting abstract (2), and news item (1). As articles were the dominant type of document, only 3,030 articles were analyzed in the following further study.

For language analysis, 3,001 articles (99.04\%) were published in English, followed by Chinese $(28 ; 0.92 \%)$, and one article in Portuguese. Obviously, English was by far the dominant language in the journals listed in the SCI-Expanded and SSCI of Web of Science database. English is indeed the main language of academic communications in many research fields.

\section{Characteristics of publication outputs}

The amounts of articles by searching the theme keywords were counted and displayed in Fig. 2. From 1996 to 2016, the annual number increased from 6 in 1996 to 532 in 2016 . The research continually fluctuated before 2005 with an upward trend, but the number of articles started to increase significantly after 2005 and rocketed from 2010 to 2016, giving evidence of increasing concern in this field. A linear curve (1996 to 2005) and power curve (2005 to 2016) were observed respectively in Fig. 3. The power curve indicated a high growth rate for publications from 2005 to 2016.

Characteristics of annual production were shown in Table 1. The average number of authors per article had an increasing trend from 1996 to 2016; overall, the average value was 3.6. The number of references cited per article fluctuated from 1996-2010 and had a slow growth trend after 2011. The average number of references cited per article was 
38.4. The length of the average article fluctuated slightly, with a comprehensive average length of 11.7 pages. The 3,030 articles contained a total of 35,014 pages. The maximum number of pages per article was 67 , while the minimum number was 2 . The maximum number of references cited per article was 325 .

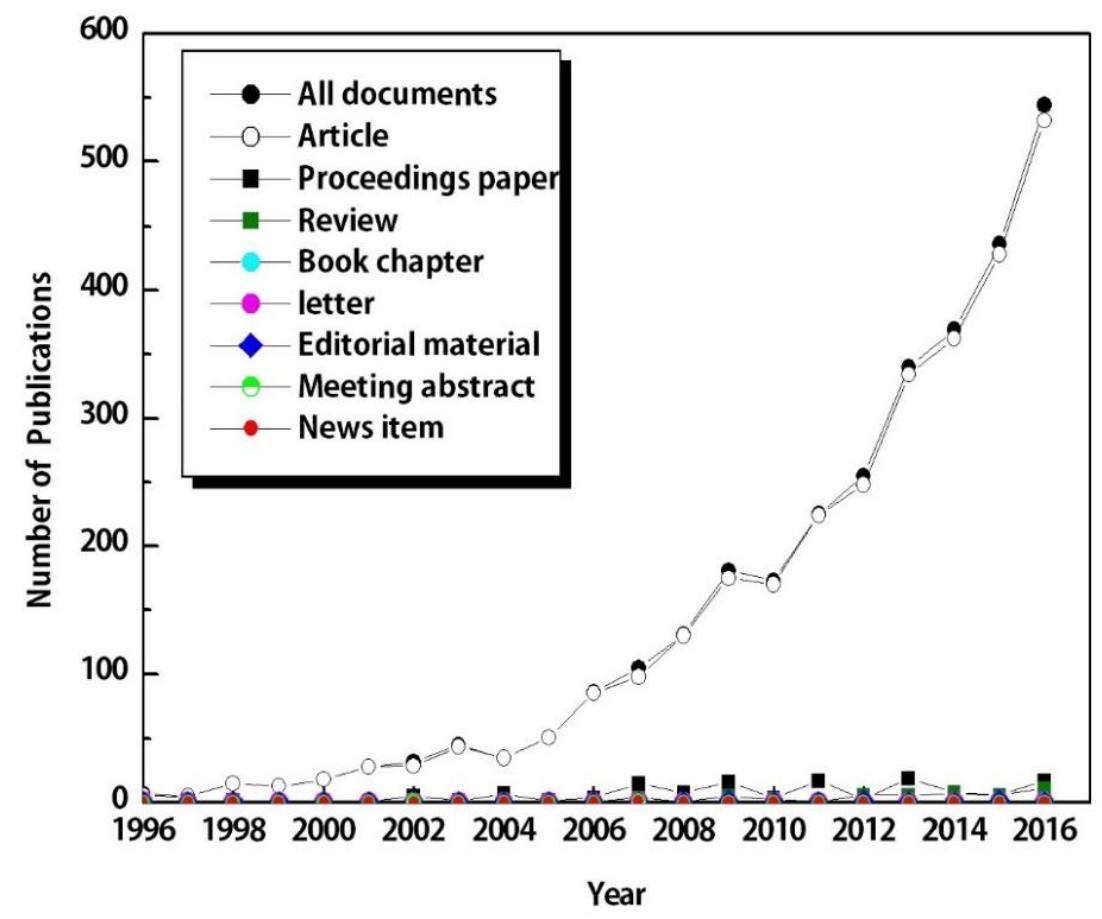

Figure 2. Relationship between number of publications and published year

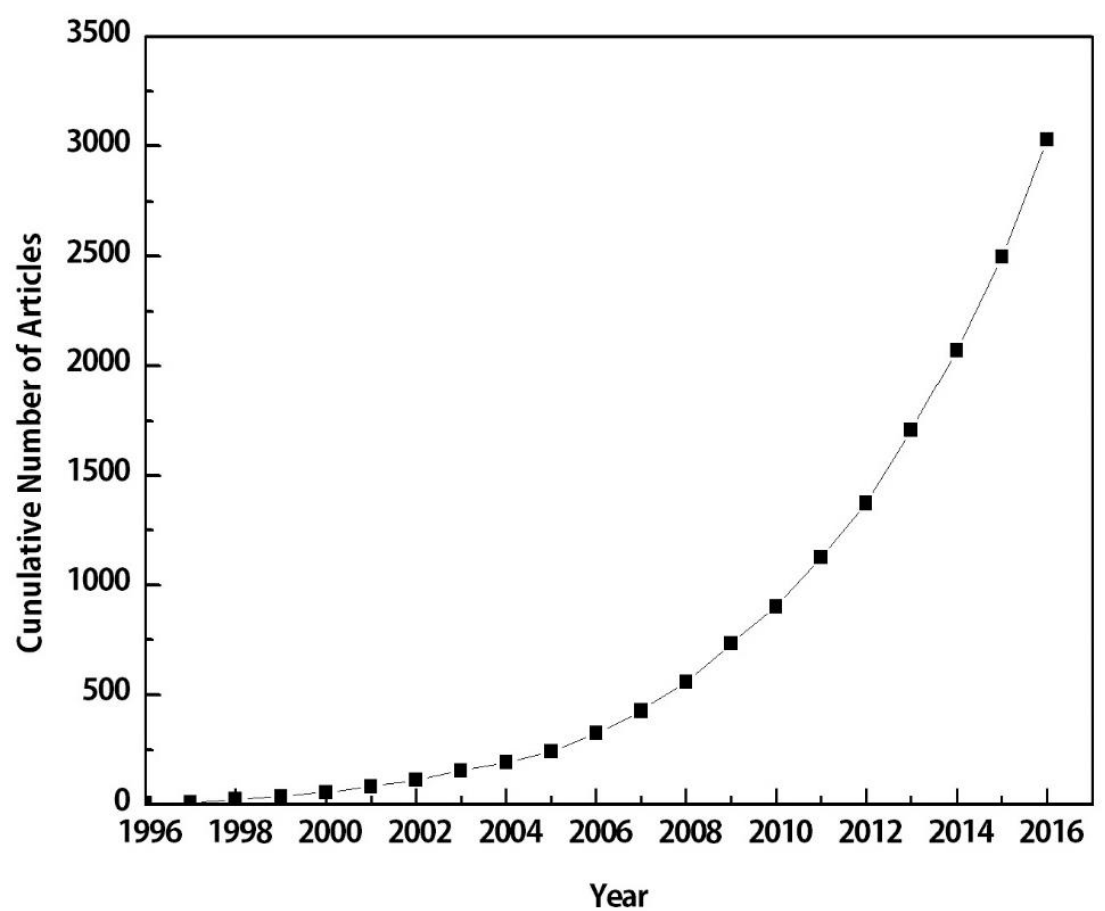

Figure 3. Relationship between cumulative number of publications and published year 
Table 1. Characteristics of publication outputs from 1996 to 2016

\begin{tabular}{c|c|c|c|c|c|c|c}
\hline Year & TP & AU & AU/TP & PG & PG/TP & NR & NR/TP \\
\hline 1996 & 6 & 11 & 1.8 & 67 & 11.2 & 224 & 37.3 \\
1997 & 5 & 11 & 2.2 & 55 & 11.0 & 178 & 35.6 \\
1998 & 15 & 35 & 2.3 & 219 & 14.6 & 522 & 34.8 \\
1999 & 13 & 42 & 3.2 & 171 & 13.2 & 477 & 36.7 \\
2000 & 18 & 73 & 4.1 & 243 & 13.5 & 493 & 27.4 \\
2001 & 28 & 95 & 3.4 & 304 & 10.9 & 777 & 27.8 \\
2002 & 29 & 140 & 4.8 & 350 & 12.1 & 806 & 27.8 \\
2003 & 44 & 155 & 3.5 & 493 & 11.2 & 1220 & 27.7 \\
2004 & 35 & 141 & 4.0 & 455 & 13.0 & 1093 & 31.2 \\
2005 & 51 & 188 & 3.7 & 565 & 11.1 & 1546 & 30.3 \\
2006 & 85 & 315 & 3.7 & 994 & 11.7 & 3169 & 37.3 \\
2007 & 98 & 392 & 4.0 & 1144 & 11.7 & 3925 & 40.1 \\
2008 & 130 & 518 & 4.0 & 1401 & 10.8 & 4933 & 37.9 \\
2009 & 175 & 663 & 3.8 & 1728 & 9.9 & 6425 & 36.7 \\
2010 & 170 & 664 & 3.9 & 1827 & 10.7 & 7648 & 45.0 \\
2011 & 224 & 895 & 4.0 & 2407 & 10.7 & 9693 & 43.3 \\
2012 & 248 & 974 & 3.9 & 2786 & 11.2 & 11526 & 46.5 \\
2013 & 334 & 1288 & 3.9 & 3831 & 11.5 & 16094 & 48.2 \\
2014 & 362 & 1450 & 4.0 & 4175 & 11.5 & 17580 & 48.6 \\
2015 & 428 & 1688 & 3.9 & 5275 & 12.3 & 21968 & 51.3 \\
2016 & 532 & 2055 & 3.9 & 6524 & 12.3 & 28779 & 54.1 \\
\hline Total & 3030 & 11793 & 76.1 & 35014 & 246.0 & 139076 & 805.5 \\
\hline Average & & & 3.6 & & 11.7 & & 38.4 \\
\hline
\end{tabular}

TP: number of publications; AU: number of authors; PG: page count; NR: cited reference count; and AU/P, PG/P and NR/P: average number of authors, pages, references per articles

\section{Authorship}

The total number of authors related to all 3,030 articles was 6,723. The average number of authors per article was 2.2. The top prolific authors did not contribute much to a significant share of publications because this research covered a variety of subjects. The most productive authors were Zhang J with 72 articles, followed by Zhang Q with 61 articles, Zhang Y with 60, Li J with 44 and Li Y with 43. The top 20 productive authors, who published no less than 25 papers, were listed in Table 2.

Table 2. Top 20 productive authors

\begin{tabular}{c|c|c|c}
\hline Name & Total publication & Name & Total publication \\
\hline Zhang J & 72 & Wang Y & 36 \\
Zhang Q & 61 & Li L & 35 \\
Zhang Y & 60 & Chen ZY & 33 \\
Li J & 44 & Chen J & 32 \\
Li Y & 43 & Wang C & 31 \\
Shen ZY & 42 & Chen L & 31 \\
Zhang L & 40 & Zhang H & 30 \\
Lu XX & 39 & Yang Y & 30 \\
Wang HJ & 37 & Yang SL & 30 \\
Xu CY & 36 & Wang L & 29 \\
\hline
\end{tabular}


However, this result possibly had a bias because some authors had the same initials. For example, author Zhang J included Zhang Jie and Zhang Jing, author Zhang Y included Zhang Yong, Zhang Yan and Zhang Yao, and author Zhang Q included Zhang Qi and Zhang Qiang. All of these authors were Chinese, because the Yangtze River was in China and Chinese scholars had greater interest in the Yangtze River.

The collaboration pattern for the productive authors using Citespace was presented in Fig. 4. The size of nodes represented the amount of publications, and a link line between two nodes indicated cooperation between two authors. The colour of the link line indicated the year of cooperation. The type of node was Citation-year-rings, representing the citation history of an author (or literature, countries, journals and institutions). The colour of the rings represented the corresponding time of citation (colour bar on the top of the figure corresponding to 1996-2016). The thickness of the ring was proportional to the number of citations in the corresponding period.

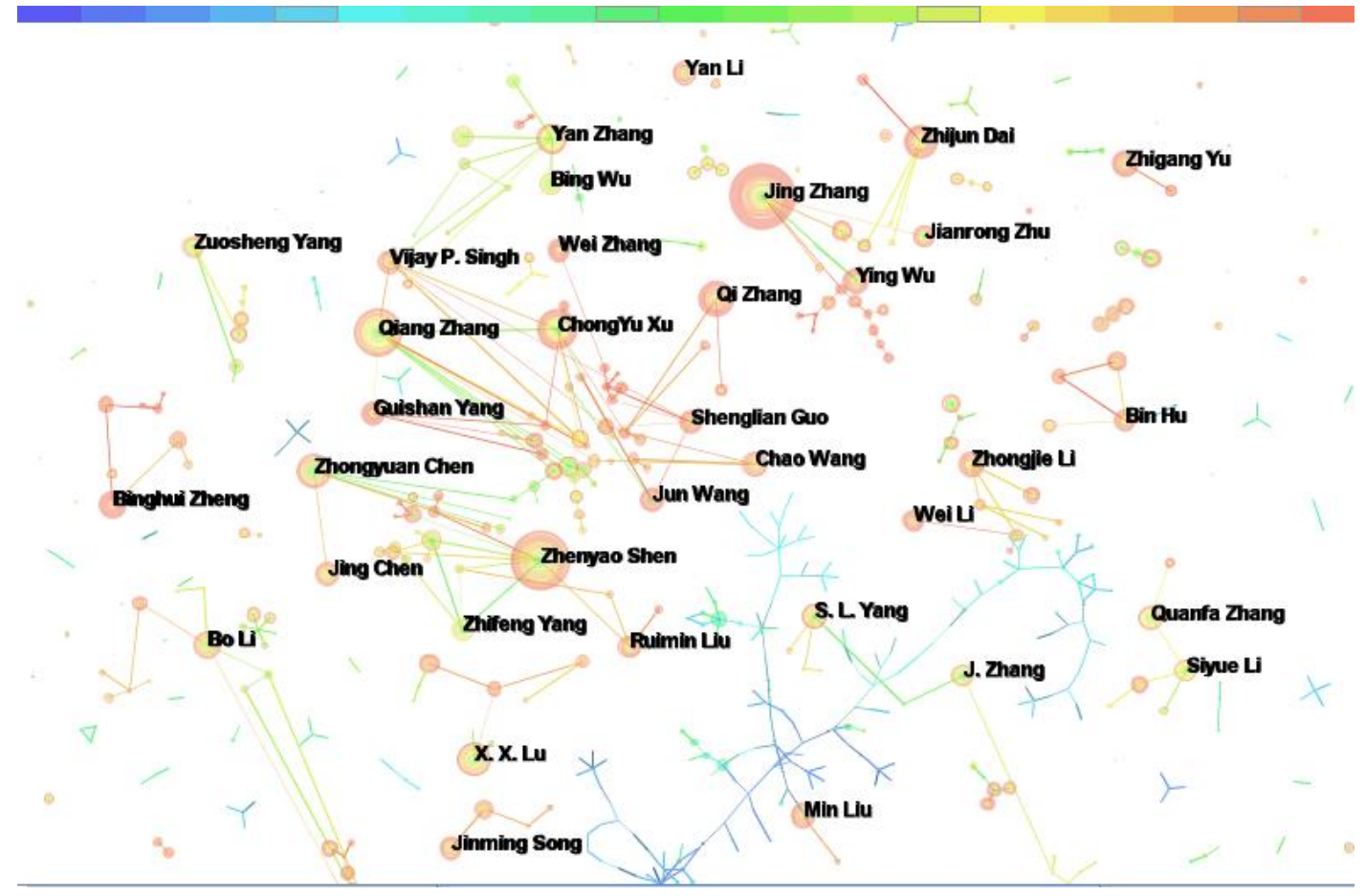

Figure 4. Combined mapping and clustering of productive authors

Several authors tended to cooperate with a small group of collaborators, generating several major clusters of authors, each of which usually had two or more core authors. Among all the authors, Zhang Jing, Shen Zhenyao, Zhang Qiang, Xu Chongyu, Zhang Qi and Zhang Yan were the most cooperative authors, who also ranked in the top ten authors. Zhang Jing's publications have increased rapidly in recent years. A bias can exist in authorship analysis when two or more authors have the same name (e.g., Zhang J). Moreover, authors with the same name may work at different institutions or in different countries over time or within the same period, thereby increasing the difficulty in analysing authorship. Therefore, it was strongly recommended that an international identity number (IIN) could be assigned to each author when first publishing a paper in a journal. It was certain that assigning and tracing IIN offered a method that allowed authorship to be assessed more appropriately (Sun et al., 2011). 


\section{Subject categories and journals}

The 3,030 articles were published in 107 subject categories in the Web of Science database. Moreover, 1,038 articles $(34.3 \%)$ were published in the category of environmental sciences, $624(20.6 \%)$ in the category of multidisciplinary geosciences, and $527(17.4 \%)$ in the category of water resources. Table 3 showed the top 10 subject categories with the most publications, the number of articles and percentage of total articles.

Table 3. Top ten subject categories with the most publications

\begin{tabular}{c|c|c|c}
\hline Ranking & Subject categories & P(Number of publications) & \% of P \\
\hline 1 & Environmental Sciences & 1038 & 34.3 \\
2 & Geosciences Multidisciplinary & 624 & 20.6 \\
3 & Water Resources & 527 & 17.4 \\
4 & Oceanography & 381 & 12.6 \\
5 & Marine Freshwater Biology & 299 & 9.9 \\
6 & Meteorology Atmospheric Sciences & 273 & 9.0 \\
7 & Geography Physical & 204 & 6.7 \\
8 & Ecology & 197 & 6.5 \\
9 & Engineering Civil & 195 & 6.4 \\
10 & Engineering Environmental & 170 & 5.6 \\
\hline
\end{tabular}

Fig. 5 indicated that publications in the category of environmental sciences rapidly increased from 2010-2016, while publications in multidisciplinary geosciences and water resources increased stably.

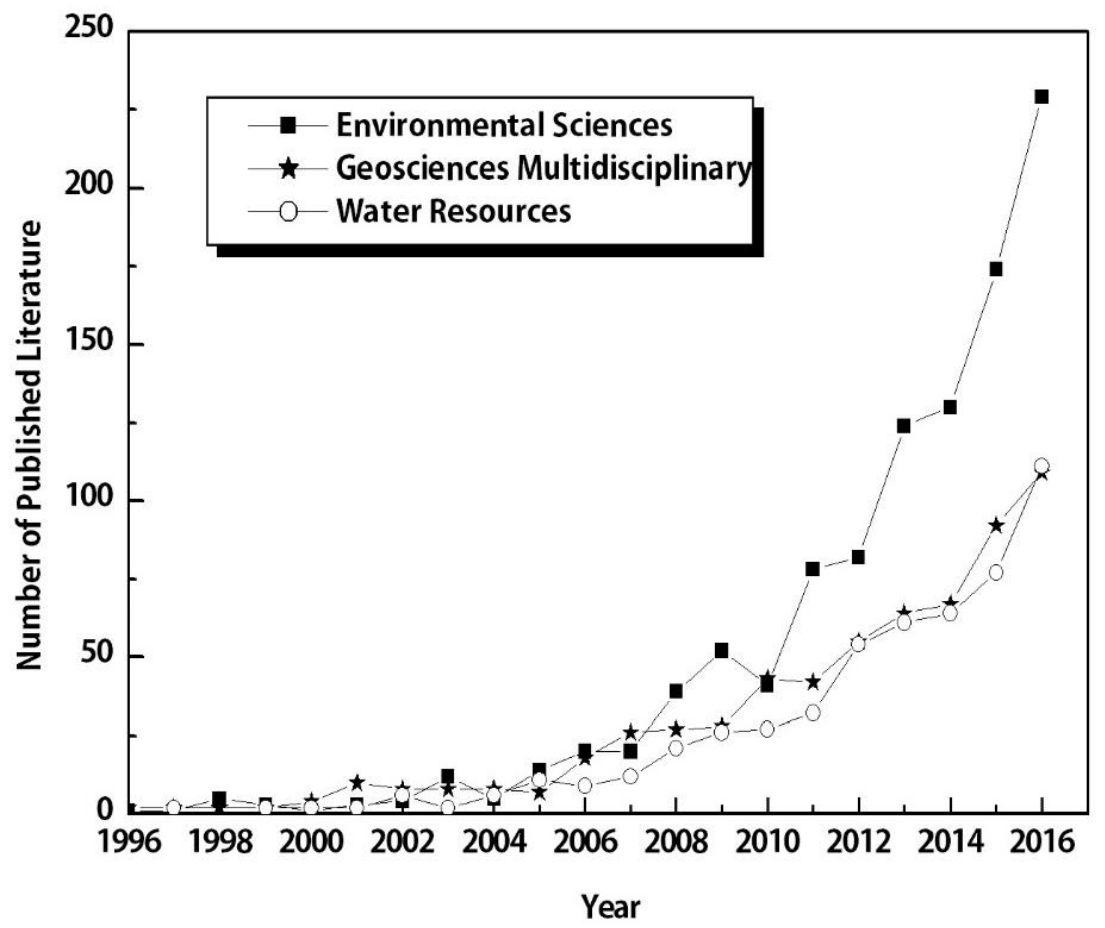

Figure 5. Comparison of total publications among top three subject categories 
The 3,030 publications were published in 598 journals. The number of publications in Environmental Science and Pollution Research and Environmental Earth Sciences ranked the first together (74,2.44\%), followed by Journal of Hydrology (71,2.34\%), Science of the Total Environment $(61,2.01 \%)$ and Estuarine Coastal and Shelf Science $(58,1.91 \%)$. The top 50 journals accounted for $51.55 \%$ of the 3,030 articles. Table 4 showed the most productive journals, whose total publication was no less than 40, with the impact factor (IF) of each journal. The IF defined by the Journal Citation Reports (JCR), was used to evaluate a journal's relative importance. In Table 4, Science of the Total Environment had the highest IF (3.976), while Chinese Journal of Oceanology and Limnology had the lowest IF (0.547).

Table 4. The 12 most-active journals

\begin{tabular}{cccc}
\hline Journal & P & \% of P & IF \\
\hline Environmental Science and Pollution Research & 74 & 2.44 & 2.760 \\
Environmental Earth Sciences & 74 & 2.44 & 1.765 \\
Journal of Hydrology & 71 & 2.34 & 3.043 \\
Science of the Total Environment & 61 & 2.01 & 3.976 \\
Estuarine Coastal and Shelf Science & 58 & 1.91 & 2.335 \\
Chinese Journal of Oceanology and Limnology & 53 & 1.75 & 0.547 \\
Continental Shelf Research & 50 & 1.65 & 2.011 \\
Chemosphere & 48 & 1.58 & 3.698 \\
Environmental Monitoring and Assessment & 46 & 1.52 & 1.633 \\
Acta Oceanologica Sinica & 46 & 1.52 & 0.631 \\
Quaternary International & 45 & 1.49 & 2.067 \\
Geomorphology & 43 & 1.42 & 2.813 \\
\hline
\end{tabular}

P: Number of publications; IF: from 2015 JCR Science Edition

\section{Countries/territories and institutions}

The contribution of different countries or territories was estimated using the location of the affiliation of at least one author. The total 3,030 articles were published by 74 countries or territories (articles from Hong Kong and Taiwan were not included in China). Table 5 presented the top 10 productive countries or territories from 1996-2016. China was the largest contributor with 2,740 (90.4\%) articles, followed by the USA, Japan and Germany with 415 (13.7\%), 122 (4.0\%) and 111 (3.7\%) articles, respectively.

Table 5. Ten most productive countries/territories

\begin{tabular}{ccc}
\hline Countries/territories & P & \% of P \\
\hline CHINA & 2740 & 90.4 \\
USA & 415 & 13.7 \\
JAPAN & 122 & 4.0 \\
GERMANY & 111 & 3.7 \\
AUSTRALIA & 93 & 3.1 \\
TAIWAN & 79 & 2.6 \\
ENGLAND & 78 & 2.6 \\
CANADA & 77 & 2.5 \\
NETHERLANDS & 69 & 2.3 \\
SOUTH KOREA & 60 & 2.0 \\
\hline
\end{tabular}

P: number of publications 
Fig. 6 showed the number of annual publications from the top three countries. China and the USA paid sustaining attention to this topic, while Japan restarted research since 2001. Furthermore, publications in China have increased sharply since 2005, increasing more than eleven-fold, from 43 in 2005 to 490 in 2016. The number of publications in the USA has slowly increased compared with China, while the number of publications in Japan has stopped and changed little.

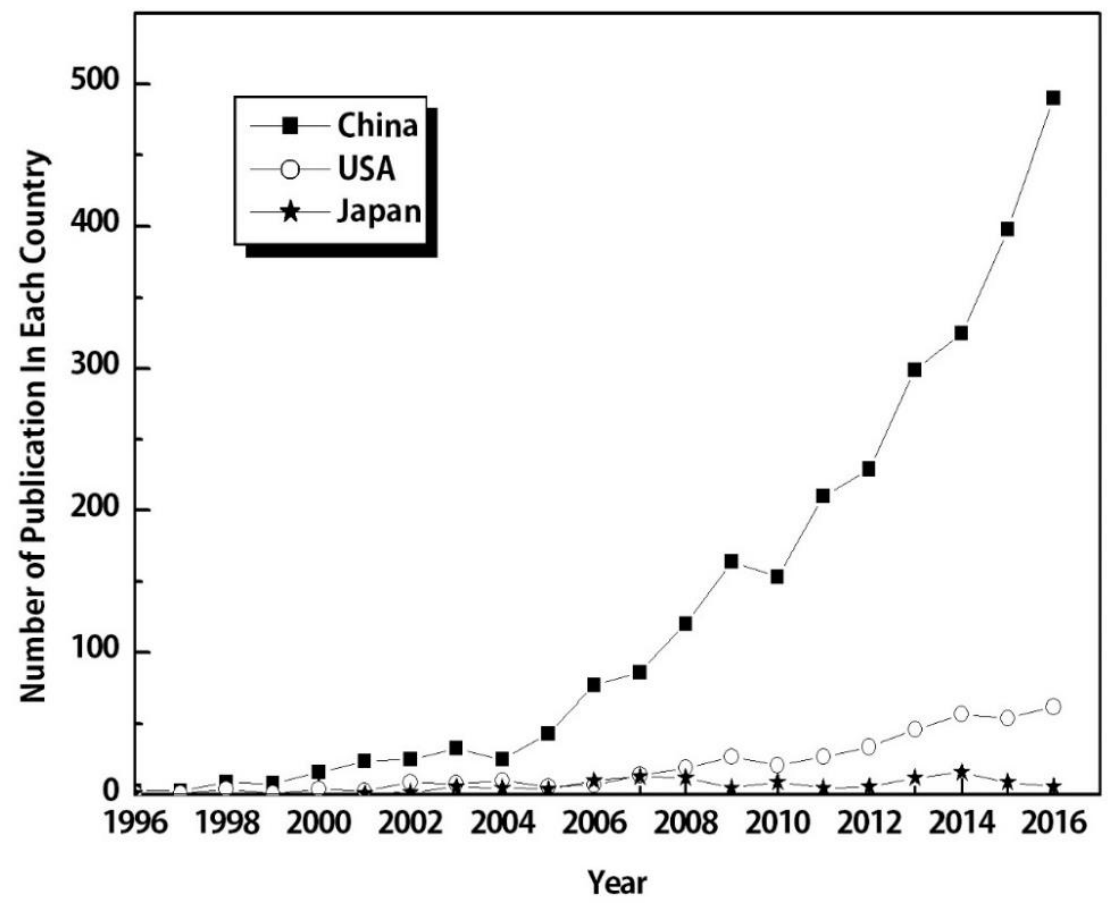

Figure 6. Number of articles from the top three countries by year

The collaboration pattern of the productive countries or territories was analyzed with Citespace in Fig. 7.

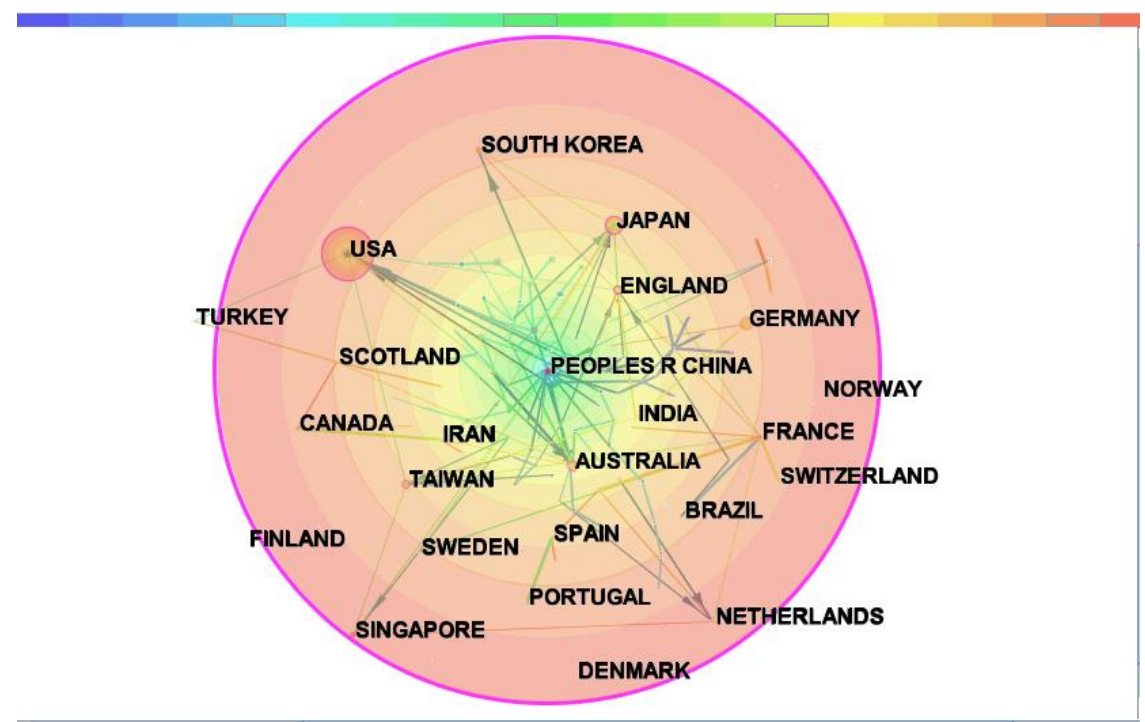

Figure 7. Combined mapping and clustering of productive countries/territories 
The outer ring of the node of China, the USA, Japan and Australia had a purple circle, indicating a high betweenness centrality. Citespace used this indicator to find and measure the importance of the countries (or literature, author, journals and institutions). Notably, China cooperated with several countries, including the USA, Japan, Australia, Singapore, and Sweden. The USA cooperated with China, England, Turkey and others.

The 3,030 articles were from 1,705 institutions. The Chinese Academy of Sciences (968, 31.9\%), East China Normal University (264), University of Chinese Academy of Sciences (260), Nanjing University (209), Ocean University of China (154), Beijing Normal University (146), Hohai University (143) and State Oceanic Administration (131) were the top eight research institutions whose total publications were at least 130 (Table 6). The most productive institutions were all in China. The Chinese Academy of Sciences, as the top one, was an integrated research centre with many independent branches throughout the country.

Table 6. Ten most productive institutions

\begin{tabular}{ccc}
\hline Institutions & P & \% of P \\
\hline Chinese Academy of Sciences & 968 & 31.9 \\
East China Normal University & 264 & 8.7 \\
University of Chinese Academy of Sciences & 260 & 8.6 \\
Nanjing University & 209 & 6.9 \\
Ocean University of China & 154 & 5.1 \\
Beijing Normal University & 146 & 4.8 \\
Hohai University & 143 & 4.7 \\
State Oceanic Administration & 131 & 4.3 \\
Wuhan University & 97 & 3.2 \\
China Meteorological Administration & 89 & 2.9 \\
\hline
\end{tabular}

P: number of publications

The collaboration pattern for the productive institutes was analyzed with Citespace as shown in Fig. 8.

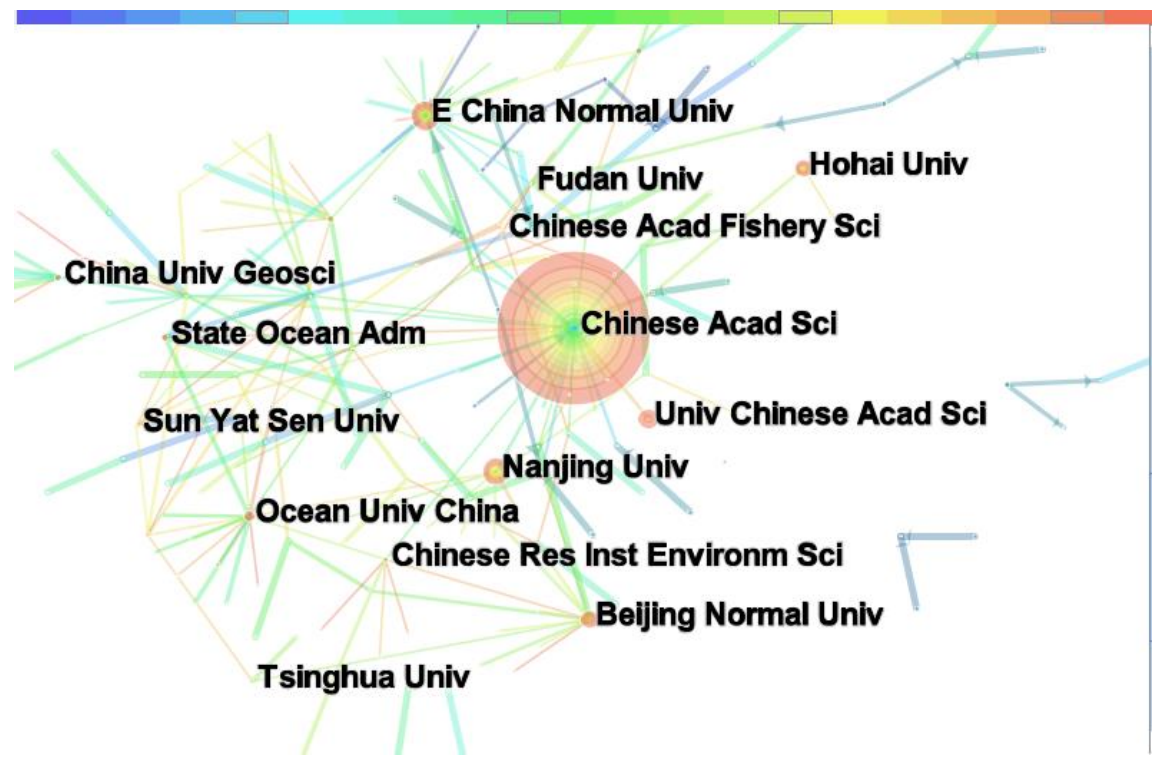

Figure 8. Combined mapping and clustering of productive institutes 
Several institutes tended to cooperate with a small group of collaborators, each of which usually had one or more core institutes, such as the Chinese Academy of Sciences and East China Normal University from China. As the most productive institution, the Chinese Academy of Sciences was in close cooperation with many institutes, such as East China Normal University, Nanjing University, the University of Chinese Academy of Sciences or the State Oceanic Administration.

\section{The most frequently cited publications}

Although a great many reports have been published, only a small number of individuals accounted for a large proportion of the citations from 1996-2016. Table 7 showed the top ten most frequently cited articles since their initial publication to April $11^{\text {st }}, 2017$.

Table 7. Ten most frequently cited articles

\begin{tabular}{|c|c|c|c|c|}
\hline TC & Title & $\begin{array}{c}\text { Publication } \\
\text { year }\end{array}$ & Author & Journal \\
\hline 611 & $\begin{array}{c}\text { Climate change will affect the Asian } \\
\text { water towers }\end{array}$ & 2010 & $\begin{array}{c}\text { Immerzeel, Walter W.; van Beek, } \\
\text { Ludovicus P. H.; Bierkens, Marc F. P. }\end{array}$ & Science \\
\hline 305 & $\begin{array}{c}\text { Flux and fate of Yangtze river } \\
\text { sediment delivered to the East China } \\
\text { Sea }\end{array}$ & 2007 & \begin{tabular}{|c|} 
Liu, J. P.; Xu, K. H.; Li, A. C.; \\
Milliman, J. D.; Velozzi, D. M.; Xiao, \\
S. B.; Yang, Z. S.
\end{tabular} & Geomorphology \\
\hline 283 & $\begin{array}{c}\text { Dynamics and distribution of natural } \\
\text { and human-caused hypoxia }\end{array}$ & 2010 & $\begin{array}{l}\text { Rabalais, N. N.; Diaz, R. J.; Levin, L. } \\
\text { A.; Turner, R. E.; Gilbert, D.; Zhang, } \\
\text { J. }\end{array}$ & Biogeosciences \\
\hline 262 & $\begin{array}{c}\text { Stepwise decreases of the Huanghe } \\
\text { (Yellow River) sediment load (1950- } \\
\text { 2005): Impacts of climate change } \\
\text { and human activities }\end{array}$ & 2007 & $\begin{array}{c}\text { Wang, Houjie; Yang, Zuosheng; Saito, } \\
\text { Yoshiki; Liu, J. Paul; Sun, Xiaoxia; } \\
\text { Wang, Yan }\end{array}$ & $\begin{array}{l}\text { Global And } \\
\text { Planetary Change }\end{array}$ \\
\hline 246 & $\begin{array}{l}\text { A drinking water crisis in Lake } \\
\text { Taihu, China: Linkage to climatic } \\
\text { variability and lake management }\end{array}$ & 2010 & \begin{tabular}{|c|} 
Qin, Boqiang; Zhu, Guangwei; Gao, \\
Guang; Zhang, Yunlin; Li, Wei; Paerl, \\
Hans W.; Carmichael, Wayne W. \\
\end{tabular} & $\begin{array}{l}\text { Environmental } \\
\text { Management }\end{array}$ \\
\hline 242 & $\begin{array}{l}\text { Atmospheric water vapor transport } \\
\text { associated with typical anomalous } \\
\text { summer rainfall patterns in China }\end{array}$ & 2005 & Zhou, TJ; Yu, RC & $\begin{array}{l}\text { Journal Of } \\
\text { Geophysical } \\
\text { Research- } \\
\text { Atmospheres }\end{array}$ \\
\hline 233 & $\begin{array}{c}\text { Ecological risk assessment of heavy } \\
\text { metals in sediment and human } \\
\text { health risk assessment of heavy } \\
\text { metals in fishes in the middle and } \\
\text { lower reaches of the Yangtze River } \\
\text { basin }\end{array}$ & 2011 & $\begin{array}{l}\text { Yi, Yujun; Yang, Zhifeng; Zhang, } \\
\text { Shanghong }\end{array}$ & $\begin{array}{l}\text { Environmental } \\
\text { Pollution }\end{array}$ \\
\hline 232 & $\begin{array}{l}\text { Atmospheric aerosol compositions } \\
\text { in China: spatial/temporal } \\
\text { variability, chemical signature, } \\
\text { regional haze distribution and } \\
\text { comparisons with global aerosols } \\
\end{array}$ & 2012 & \begin{tabular}{|} 
Zhang, X. Y.; Wang, Y. Q.; Niu, T.; \\
Zhang, X. C.; Gong, S. L.; Zhang, Y. \\
M.; Sun, J. Y.
\end{tabular} & $\begin{array}{l}\text { Atmospheric } \\
\text { Chemistry And } \\
\text { Physics }\end{array}$ \\
\hline 226 & $\begin{array}{l}\text { Organochlorine pesticides in the air } \\
\text { around the Taihu Lake, China }\end{array}$ & 2004 & $\begin{array}{c}\text { Qiu, XH; Zhu, T; Jing, L; Pan, HS; Li, } \\
\text { QL; Miao, GF; Gong, JC }\end{array}$ & $\begin{array}{l}\text { environmental } \\
\text { Science \& } \\
\text { Technology } \\
\end{array}$ \\
\hline 219 & $\begin{array}{c}\text { The Huanghe (Yellow River) and } \\
\text { Changjiang (Yangtze River) deltas: } \\
\text { a review on their characteristics, } \\
\text { evolution and sediment discharge } \\
\text { during the Holocene }\end{array}$ & 2001 & Saito, Y; Yang, ZS; Hori, K & Geomorphology \\
\hline
\end{tabular}


The most frequently cited article was "Climate change will affect the Asian water towers", published in Science $(\mathrm{IF}=34.661)$ by Immerzeel et al. in 2010 with 611 citations. It was reported that reductions in glacier and snow coverage would affect river discharge and food security in the basins of the Indus, Ganges, Brahmaputra, Yangtze and Yellow rivers (Immerzeel et al., 2010). The second, titled "Flux and fate of Yangtze river sediment delivered to the East China Sea" with 305 citations, was published in Geomorphology $(\mathrm{IF}=2.813)$ by Liu et al. in 2007. Their results showed that sedimentation accumulation apparently increased, reflecting the evolution of the Yangtze estuary and increased land erosion due to human activities (Liu et al., 2007).

The most frequently cited articles in Table 7 could indicate the research hotspots, including impacts of climate change and human activities, precipitation characteristics, variation of sediment flux, environmental pollution and ecological concerns.

\section{Author keywords}

Author keywords were used to reveal the internal structure of the authors' reasoning. Keywords analysis can offer information about research trends (Min et al., 2010). A diverse research focus may lead to the fact that the use frequencies of a large number of keywords are less than three. The top 20 commonly used keywords for this study are presented in Table 8 and Fig. 9.

Table 8. Top 20 most commonly used author keywords from 1996 to 2016

\begin{tabular}{cccc}
\hline Author keywords & Frequency & Author keywords & Frequency \\
\hline Yangtze River & 646 & Climate change & 120 \\
China & 572 & Estuary & 117 \\
East China sea & 243 & Eutrophication & 112 \\
Water & 237 & Phosphorus & 110 \\
Sediment & 173 & Nitrogen & 105 \\
Variability & 155 & Transport & 104 \\
Impacts & 146 & Dynamics & 103 \\
Model, precipitation & 142 & Continental shelf & 98 \\
Basin & 136 & Discharge & 92 \\
River & 122 & Management & 89 \\
\hline
\end{tabular}

Apart from the search words and the common words of "Yangtze River", "water", "China", "East China sea", "river basin", the most-frequently used keywords were "sediment", "variability", "impacts", "model", "precipitation", "climate change", "estuary", "eutrophication", "phosphorus", "nitrogen", "transport", "dynamics", "continental shelf", "discharge" and "management". These keywords implied that the studies were mainly focused on variability of sediment, precipitation and pollutants, impacts of climate change and human activities, model analysis, estuarine ecology, eutrophication and water pollution, dynamics characteristics of environmental variables and watershed management. Fig. 9 showed the relationship pattern for the keywords using Citespace. It indicated that three or more related keywords could describe the research focus of an article and help readers to recognize its major topics. 


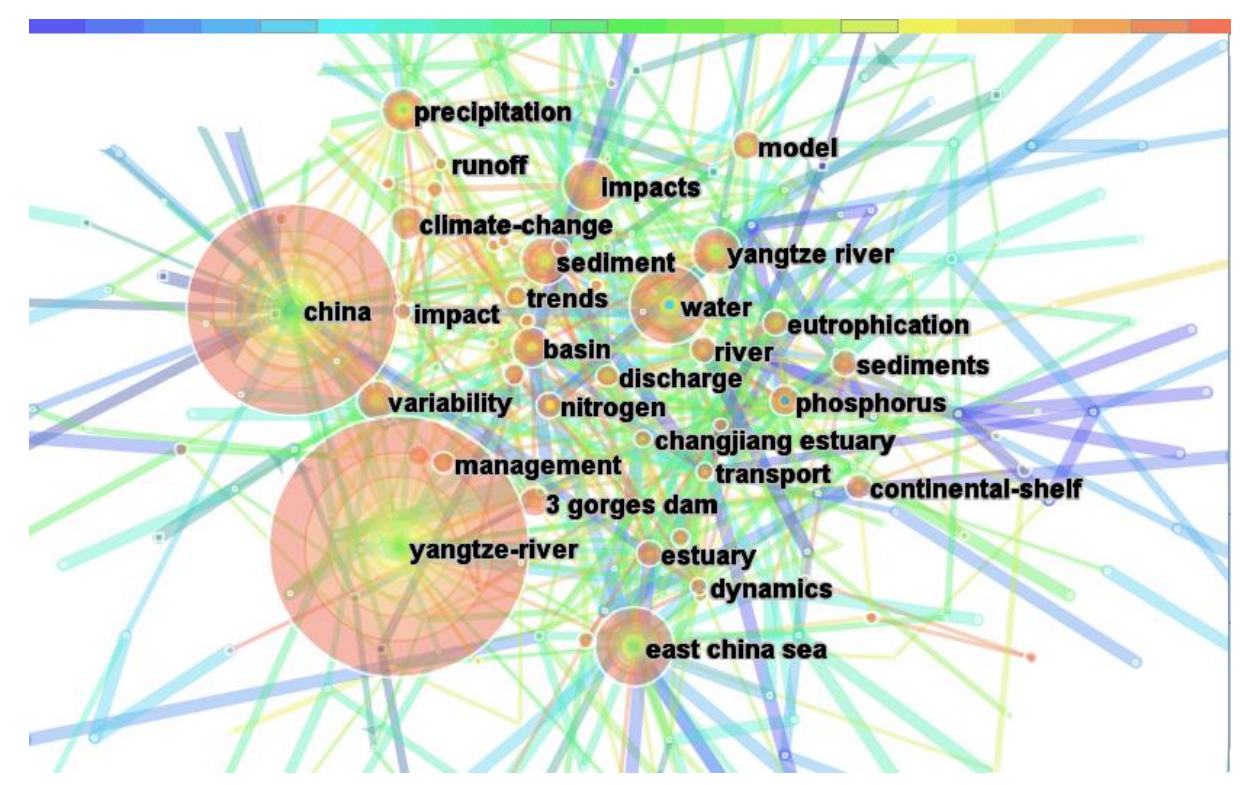

Figure 9. Combined mapping and clustering of keywords

\section{Discussions}

The most frequently cited publications and author keywords can provide the clues for the potential future of water research on the Yangtze River. However, there were limitations to use the two indicators as a tool in the evaluation of publications and journals. For instance, high citation counts of a paper might not indicate its high quality. A paper might be frequently cited due to its flaws or criticisms and unconventional citation behaviours. Author keywords can help in the search for references. Keywords were selected by authors with different options and aims, possibly for gaining more citations. Some keywords might be inappropriate due to the lack in the peer-review or scientific appraisals. Keywords have to be selected carefully to represent the main content of a paper and its specific field or sub-field.

What's more, the bibliometric analysis is not a panacea for understanding the evolution of science and research evaluations (Blouin et al., 2013; Hicks et al., 2015). Using a range of quantitative measures, bibliometrics can assess the impact of research outputs. Yet these measures might provide only one part of the picture. There were also limitations in database used by the bibliometric analysis, such as language and geographic coverage, subject depth and breadth, recording formats and depth of backfiles. The bibliometric analysis is not a replacement for qualitative methods of evaluation. Therefore, the in-depth and extensive literature reading could be used in conjunction with the bibliometric analysis to address these limitations.

\section{Research trends}

Based on the above bibliometric analysis results, traditional literature reviews were conducted as a complement to further identify the hotspots and trends of water research on the Yangtze River. Impacts of climate change and human activities and the adaptation strategies could be the mainstream directions in this field. Specific research concerns could also consist of the following aspects. 


\section{Climate change}

Climate change is a major challenge of increasing concern to water security in the Yangtze River Basin and China (Jiang, 2015). A large number of studies have been published about impacts of climate change on the temperature, precipitation, evaporation, water level, streamflow, sediment and other environmental variables of the Yangtze River (Wang et al., 2016). To some extent, upstream meltwater has effects on water availability and food security in the Yangtze River Basin (Immerzeel et al., 2010). The Yangtze River was at a boundary between decreasing precipitation in the NorthEast of China and increasing precipitation in the South-East over recent decades, due to the weakening of the East Asian summer monsoon (Wang et al., 2012). This has caused a small, but statistically insignificant, increase in discharge for the Yangtze Basin since 1960 (Piao et al., 2010). It was observed that there was a decline trend of Yangtze River water and sediment discharge, as a result of impact from natural and anthropogenic changes (Yang et al., 2015). Yet uncertainties in the environmental variables in the Yangtze River will remain due to the uncertainties in climate change projections (Birkinshaw et al., 2017). Climate change would aggravate the challenges of water resource management by introducing greater variability in water systems and by changing flow conditions in surface water systems, amplifying the existing patterns of shortage and excess (Wang et al., 2012; Jiang, 2015).

\section{Water conservancy development}

With the rapid socio-economic development, a huge number of water conservancy projects have been constructed in the Yangtze River Basin, such as dams, hydropower stations, reservoirs, water supply and drainage infrastructure, and water transfer projects. These water projects have brought tremendous benefits in flood control, water scarcity alleviation, clean energy generation and have supported the food security and overall economic development. However, the massive projects have caused many problems concerning the environment impacts, degradation of freshwater and soil ecosystems, soil and river erosion, and large population resettlements (Liu et al., 2013). For instance, construction of $\sim 50,000$ dams throughout the Yangtze River watershed has resulted in downstream channel erosion and coarsening of bottom sediment, and erosion of the Yangtze's subaqueous delta (Yang et al., 2011). A report concluded five crucial environmental aspects and associated causal factors of the Three Gorges Project, including human resettlement and the carrying capacity of local environments, water quality, reservoir sedimentation and downstream riverbed erosion, soil erosion, and seismic activity and geological hazards ( $\mathrm{Xu}$ et al., 2013). Water transfers from the Yangtze River, including the South-to-North Water Diversion Project, have great impacts on water security especially in the lower Yangtze River areas (Chen et al., 2013; Finlayson et al., 2013). The hydrological and eco-environmental effects of mega water projects and the corresponding long-term monitoring and strategies have become one of the top topics of attention (Zhang et al., 2015).

\section{Environmental issues and solutions}

Besides the environmental impacts mentioned above, the environmental problems might be severe and even getting worse in the Yangtze River Basin. These issues could range from air pollution, biodiversity losses, cropland losses, depleted fisheries, disappearing wetlands, and increasing frequency and scale of human-induced natural 
disasters, to interrupted river flow, soil erosion, trash accumulation, and water pollution and shortages (Liu and Diamond, 2005). Especially, the Yangtze River was reported as a major regional source of plastic input into the marine environment (Lebreton et al., 2017). Widespread occurrence of antibiotic residues was even observed in the surface water of the Yangtze River (Yan et al., 2013). The Yangtze River is becoming increasingly polluted with the worsening water quality. This will threaten the health of rare species and millions of people living in this river basin. To cope with these issues, many measures and projects have been taken, including water and soil conservation, ecological restoration, biodiversity conservation, non-point source pollution control, sewage treatment, organic matter degradation, and environmental policy and governance. Yet the Yangtze River Basin is confronted with the dual tasks of economic development and environmental protection. Environmental issues and solutions in the Yangtze River Basin remain to be explored as the hot topic in this research field.

\section{Water-food-energy nexus}

Water, food and energy are crucial resources for the sustainable development of mankind. Driven by climate change, economic growth, urbanization and population increase, China has been facing increasingly severe water, food and energy security issues (Jiang, 2015). The interaction and the interlinked security risks of the water, food, and energy system have become a major challenge in the world. A nexus perspective, named the Water-Food-Energy (WFE) nexus, has been initiated on a global level to integrate management and governance across all three resources-related sectors and scales (Hoff, 2011; Zhang et al., 2018). Its aims are to increase efficiency, reduce tradeoffs, build synergies, and improve governance across sectors (Hoff, 2011). China containing the Yangtze River Basin has attracted increasing attention to the WFE nexus research. It is noteworthy that China' government has incorporated the WFE nexus security into the National Key Research and Development Program from 2017, which included the Yangtze River Basin as a typical case area. It can be predicted that the WFE nexus with interdisciplinary solutions will become a hotspot of water research on the Yangtze River in the coming years.

\section{Conclusion}

Based on the 3,030 publications obtained from the SCI-Expanded and SSCI of Web of Science database, a bibliometric analysis concerning the global trend was conducted to provide a systematic overview of water research on the Yangtze River from 1996 to 2016. There were eight document types related to this research, and most were published in English. The number of publications per year was growing significantly. The 10 most productive authors were all Chinese. Literature was published in 598 journals in 107 subject categories from 74 countries/territories. Environmental Science and Pollution Research ranks the first journal in the number of publications, followed by Environmental Earth Sciences and Journal of Hydrology. Among the 74 involved countries, China, the USA and Japan were the three dominant countries. Chinese Academy of Sciences was the most representative among the 1,705 institutions. Author keywords analysis offered interesting insights into the publications, including "sediment", "variability", "impacts", "model", "precipitation", "climate change", "estuary", "eutrophication", "phosphorus", and "nitrogen". Based on the bibliometric analysis results and traditional literature reviews, the hotspots and trends in this field 
included impacts of climate change and human activities and the adaptation strategies. Additional studies should also be focused on water conservancy development, environmental issues and solutions, and the Water-Food-Energy nexus. This analysis provided a holistic picture of the related literatures and the research directions. These findings will be helpful to provide references for future studies on the Yangtze River.

Acknowledgements. This research is supported by the National Key Research and Development Program of China (2017YFC040320502), the Fundamental Research Funds for the Central Universities (2018B12414), Australian Research Council for Discovery Project Grant (DP170104138) and a Project Funded by the Priority Academic Program Development of Jiangsu Higher Education Institutions (PAPD). We thank the anonymous reviewers and the editors for their constructive comments, which helped us to improve the manuscript.

\section{REFERENCES}

[1] Birkinshaw, S. J., Guerreiro, S. B., Nicholson, A., Liang, Q., Quinn, P., Zhang, L., He, B., Yin, J., Fowler, H. J. (2017): Climate change impacts on Yangtze River discharge at the Three Gorges Dam. - Hydrology \& Earth System Sciences 21(4):1911-1927.

[2] Blouin, M., Sery, N., Cluzeau, D., Brun, J.-J., Bédécarrats, A. (2013): Balkanized research in ecological engineering revealed by a bibliometric analysis of earthworms and ecosystem services. - Environ Manage 52: 309-320.

[3] Chen, C. (2004): Searching for intellectual turning points: Progressive knowledge domain visualization. - Proceedings of the National Academy of Sciences 101: 5303-5310.

[4] Chen, C. (2006): CiteSpace II: Detecting and visualizing emerging trends and transient patterns in scientific literature. - J Am Soc Inf Sci Technol 57: 359-377.

[5] Chen, C., Ibekwe-SanJuan, F., Hou, J. (2010): The structure and dynamics of cocitation clusters: A multiple-perspective cocitation analysis. - Journal of the American Society for Information Science and Technology 61: 1386-1409.

[6] Chen, D., Webber, M., Finlayson, B., Barnett, J., Chen, Z., Wang, M. (2013): The impact of water transfers from the lower Yangtze River on water security in Shanghai. - Applied Geography 45: 303-310.

[7] Finlayson, B. L., Barnett, J., Wei, T., Webber, M., Li, M., Wang, M. Y., Chen, J., Xu, H., Chen, Z. (2013): The drivers of risk to water security in Shanghai. - Regional Environmental Change 13: 329-340.

[8] Gu, C., Hu, L., Zhang, X., Wang, X., Guo, J. (2011): Climate change and urbanization in the Yangtze River Delta. - Habitat Int 35: 544-552.

[9] Hicks, D., Wouters, P., Waltman, L., Rijcke, S.D., Rafols, I. (2015): Bibliometrics: the Leiden Manifesto for research metrics. - Nature 520: 429-431.

[10] Hoff, H. (2011): Understanding the nexus. background paper for the Bonn2011 Conference: the water, energy and food security nexus. - Stockholm Environment Institute, Stockholm.

[11] Immerzeel, W. W., Van Beek, L. P., Bierkens, M. F. (2010): Climate change will affect the Asian water towers. - Science 328: 1382-1385.

[12] Jiang, Y. (2015): China's water security: current status, emerging challenges and future prospects. - Environ Sci Policy 54: 106-125.

[13] Lebreton, L. C. M., van der Zwet, J., Damsteeg, J.-W., Slat, B., Andrady, A., Reisser, J. (2017): River plastic emissions to the world's oceans. - Nature Communications 8: 15611.

[14] Li, J., Zhang, Y., Wang, X., Ho, Y.-S. (2009): Bibliometric analysis of atmospheric simulation trends in meteorology and atmospheric science journals. - Croatica Chemica Acta 82: 695-705. 
[15] Liu, J., Diamond, J. (2005): China's environment in a globalizing world. - Nature 435: 1179.

[16] Liu, J., Xu, K., Li, A. E. A., Milliman, J., Velozzi, D., Xiao, S., Yang, Z. (2007): Flux and fate of Yangtze River sediment delivered to the East China Sea. - Geomorphology 85: 208-224.

[17] Liu, J., Zang, C., Tian, S., Liu, J., Yang, H., Jia, S., You, L., Liu, B., Zhang, M. (2013): Water conservancy projects in China: achievements, challenges and way forward. Global Environmental Change 23: 633-643.

[18] Liu, X., Zhang, L., Hong, S. (2011): Global biodiversity research during 1900-2009: a bibliometric analysis. - Biodivers Conserv 20: 807-826.

[19] Min, K., Zhang, Z., Wright, J., Ma, Y., (2010): Decomposing background topics from keywords by principal component pursuit. - Proceedings of the 19th ACM international conference on Information and knowledge management. ACM, 269-278.

[20] Pörtner, H.-O. (2008): Ecosystem effects of ocean acidification in times of ocean warming: a physiologist's view. - Mar Ecol Prog Ser 373: 203-217.

[21] Piao, S., Ciais, P., Huang, Y., Shen, Z., Peng, S., Li, J., Zhou, L., Liu, H., Ma, Y., Ding, Y. (2010): The impacts of climate change on water resources and agriculture in China. Nature 467: 43-51.

[22] Qiu, J. (2009): Chinese dam may be a methane menace. - Nature. doi:10.1038/news.2009.962

[23] Rinia, E. J., Van Leeuwen, T. N., Van Vuren, H. G., Van Raan, A. F. (1998): Comparative analysis of a set of bibliometric indicators and central peer review criteria: Evaluation of condensed matter physics in the Netherlands. - Research policy 27: 95-107.

[24] Schmidt, C., Krauth, T., Wagner, S. (2017): Export of plastic debris by rivers into the sea. - Environmental science \& technology 51: 12246-12253.

[25] Sun, J., Ni, J., Ho, Y.-S. (2011): Scientometric analysis of coastal eutrophication research during the period of 1993 to 2008. - Environment, development and sustainability 13: 353-366.

[26] Wang, H.-J., Sun, J.-Q., Chen, H.-P., Zhu, Y.-L., Zhang, Y., Jiang, D.-B., Lang, X.-M., Fan, K., Yu, E.-T., Yang, S. (2012): Extreme climate in China: Facts, simulation and projection. - Meteorol Z 21: 279-304.

[27] Wang, H., Wang, J., Liu, R., Yu, W., Shen, Z. (2015): Spatial variation, environmental risk and biological hazard assessment of heavy metals in surface sediments of the Yangtze River estuary. - Mar Pollut Bull 93: 250-258.

[28] Wang, W., Zou, S., Shao, Q., Xing, W., Chen, X., Jiao, X., Luo, Y., Yong, B., Yu, Z. (2016): The analytical derivation of multiple elasticities of runoff to climate change and catchment characteristics alteration. - J Hydrol 541: 1042-1056.

[29] Xu, X., Tan, Y., Yang, G. (2013): Environmental impact assessments of the Three Gorges Project in China: Issues and interventions. - Earth-Sci Rev 124: 115-125.

[30] Yan, C., Yang, Y., Zhou, J., Liu, M., Nie, M., Shi, H., Gu, L. (2013): Antibiotics in the surface water of the Yangtze Estuary: occurrence, distribution and risk assessment. Environ Pollut 175: 22-29.

[31] Yang, S., Milliman, J., Li, P., Xu, K. (2011): 50,000 dams later: erosion of the Yangtze River and its delta. - Global Planet Change 75: 14-20.

[32] Yang, S., Xu, K., Milliman, J., Yang, H., Wu, C. (2015): Decline of Yangtze River water and sediment discharge: Impact from natural and anthropogenic changes. - Scientific reports 5: 12581.

[33] Zeng, X. (1990): Fishery resources of the Yangtze River basin. - Marine Press, Beijing, China.

[34] Zhang, C., Chen, X., Li, Y., Ding, W., Fu, G. (2018): Water-energy-food nexus: Concepts, questions and methodologies. - J. Clean. Prod. 195. DOI: 10.1016/j.jclepro.2018.05.194\} 
[35] Zhang, L., Li, S., Loáiciga, H. A., Zhuang, Y., Du, Y. (2015): Opportunities and challenges of interbasin water transfers: a literature review with bibliometric analysis. Scientometrics 105: 279-294.

[36] Zhao, Y., Wu, B., Zeng, Y. (2013): Spatial and temporal patterns of greenhouse gas emissions from Three Gorges Reservoir of China. - Biogeosciences 10: 1219-1230.

[37] Zhou, X., Guang, X., Sun, D., Xu, S., Li, M., Seim, I., Jie, W., Yang, L., Zhu, Q., Xu, J. (2018): Population genomics of finless porpoises reveal an incipient cetacean species adapted to freshwater. - Nature Communications 9: 1276. 